Research, Society and Development, v. 9, n. 8, e947985532, 2020

(CC BY 4.0) | ISSN 2525-3409 | DOI: http://dx.doi.org/10.33448/rsd-v9i8.5532

Perfil socioeconômico dos consumidores e comerciantes de frutas de Barra-BA

Socioeconomic profile of consumers and merchants fruit from Barra-BA

Perfil socioeconómico de consumidores y comerciantes de frutas en Barra-BA

Recebido: 12/06/2020 | Revisado: 03/07/2020 | Aceito: 22/07/2020 | Publicado: 02/08/2020

\title{
Iurimon Oliveira
}

ORCID: https://orcid.org/0000-0003-2635-3501

Universidade Federal do Oeste da Bahia, Brasil

E-mail: iurimonoliveira@gmail.com

César Fernandes Aquino

ORCID: https://orcid.org/0000-0003-0725-011X

Universidade Federal do Oeste da Bahia, Brasil

E-mail: cesar.aquino@ufob.edu.br

Antônia Mirian Nogueira de Moura Guerra

ORCID: https://orcid.org/0000-0001-9475-306X

Universidade Federal do Oeste da Bahia, Brasil

E-mail: mirianagronoma@hotmail.com

Francisco das Chagas Bezerra Neto

ORCID: https://orcid.org/0000-0001-6232-4383

Universidade Federal de Campina Grande, Brasil

E-mail: chagasneto237@gmail.com

Clarice Ribeiro Alves Caiana

ORCID: https://orcid.org/0000-0002-5374-1617

Universidade Federal de Campina Grande, Brasil

E-mail: clariceribeirocaiana@gmail.com

Aline Carla de Medeiros

ORCID: https://orcid.org/0000-0002-0161-3541

Universidade Federal de Campina Grande, Brasil

E-mail: alinecarla.edu@gmail.com

Patrício Borges Maracajá

ORCID: https://orcid.org/0000-0003-4812-0389

Universidade Federal de Campina Grande, Brasil E-mail: patriciomaracaja@gmail.com 


\title{
Resumo
}

Objetivou-se identificar o perfil dos consumidores e dos comerciantes de frutas da cidade de Barra-BA, de forma a gerar dados informativos acerca do comércio e consumo de frutas, com vistas à proposição de melhorias e exploração de novos nichos do mercado de frutas da cidade. As entrevistas foram realizadas por meio de aplicação de questionário socioeconômico, aplicado no comércio varejista de frutas e feiras livres da cidade. $60,5 \%$ dos consumidores são do sexo feminino, sendo $45 \%$ com idade entre 20 e 35 anos. A frequência de compra de frutas é semanal (62,5\%), e a maioria dos consumidores $(36 \%)$ gasta em média de $\mathrm{R} \$ 21$ a 30 por compra de frutas. Para $69 \%$ a qualidade das frutas atende a suas exigências parcialmente. Os sacolões se destacam como local de preferência para compra de frutas, representando 51\%. A banana é a fruta mais consumida pelos entrevistados (82\%). 60,4\% dos comerciantes não compram frutas na cidade, por não encontrar, sendo a cidade de Irecê-BA a principal fonte fornecedora de frutas $(92,6 \%)$, que são transportadas em caminhões baú fechado $(46,4 \%)$ e caminhões com carroceria aberta (43,9\%). A perda pós-colheita é unanime entre os comerciantes, sendo que a maioria não sabe como resolver o problema. A frequência de compras do consumidor de frutas é influenciada pela logística dos comerciantes que costumam renovar as prateleiras apenas uma vez por semana. Melhorias nos comércios de frutas na cidade devem ser incentivadas para atender melhor a população e evitar perdas póscolheita.

Palavras-chave: Comercialização de frutas; Consumo; Fruticultura.

\begin{abstract}
The objective identify the profile of consumers and traders of fruits of the city of Barra-BA, in order to generate informative data about fruit trade and consumption, with a view to proposing improvements and exploration of new niches in the fruit market city. The interviews were conducted by applying a socioeconomic questionnaire, applied to the retail trade of fruits and free markets in the city. $60.5 \%$ of consumers are female, $45 \%$ aged between 20 and 35 years. The frequency of buying fruit is weekly (62.5\%), and most consumers (36\%) spend on average $\mathrm{R} \$ 21$ to 30 per fruit purchase. For $69 \%$ the quality of the fruit partially meets their requirements. The bags stand out as the preferred place to buy fruit, representing $51 \%$. Banana is the most consumed fruit by respondents (82\%). $60.4 \%$ of traders do not buy fruits in the city because they can not find, being the city of Irecê-BA the main source of fruit supply (92.6\%), which are transported in closed box trucks (46.4\%) and trucks. with open body (43.9\%). Postharvest loss is unanimous among traders, and most do not know how to
\end{abstract}


solve the problem. The frequency of fruit consumer purchases is influenced by the logistics of merchants who usually renew shelves only once a week. Improvements in the city's fruit trade should be encouraged to better serve the population and prevent postharvest losses.

Keywords: Marketing of fruit; Consumption; Fruit.

\section{Resumen}

El objetivo era identificar el perfil de los consumidores y comerciantes de frutas en la ciudad de Barra-BA, con el fin de generar datos informativos sobre el comercio y el consumo de frutas, con el fin de proponer mejoras y explorar nuevos nichos en el mercado de frutas en la ciudad. Ciudad. Las entrevistas se llevaron a cabo mediante la aplicación de un cuestionario socioeconómico, aplicado en el comercio minorista de frutas y mercados abiertos en la ciudad. El 60,5\% de los consumidores son mujeres, y el $45 \%$ tiene entre 20 y 35 años. La frecuencia de compra de fruta es semanal (62,5\%), y la mayoría de los consumidores (36\%) gastan un promedio de $\mathrm{R} \$ 21$ a 30 por compra de fruta. Para el 69\%, la calidad de la fruta cumple parcialmente con sus requisitos. Los sacolões se destacan como el lugar preferido para comprar fruta, representando el 51\%. El plátano es la fruta más consumida por los encuestados (82\%). El 60,4\% de los comerciantes no compran fruta en la ciudad, porque no pueden encontrarla, siendo la ciudad de Irecê-BA la principal fuente de fruta $(92,6 \%)$, que se transportan en camiones troncales cerrados $(46,4 \%)$ y camiones con carrocerías abiertas $(43,9 \%)$. La pérdida posterior a la cosecha es unánime entre los comerciantes, y la mayoría no sabe cómo resolver el problema. La frecuencia de las compras de fruta de los consumidores está influenciada por la logística de los comerciantes que generalmente renuevan sus estantes solo una vez por semana. Se deben fomentar las mejoras en el comercio de frutas en la ciudad para servir mejor a la población y evitar pérdidas posteriores a la cosecha.

Palabras llave: Comercialización de fruta; Consumo; Fruticultura.

\section{Introdução}

O Brasil ocupa a terceira posição no ranking mundial de produção de frutas, ficando atrás apenas da China e da Índia. A grande variedade de espécies e cultivares plantadas no país permite a oferta de frutas frescas durante o ano todo, em diversas regiões do país. A área plantada com as 23 espécies de frutíferas mais produzidas no Brasil reduziu no ano de 2017, porém, a quantidade produzida foi superior em relação a 2016 (kist et al., 2018). 
Apesar da grande produção e diversificação das frutíferas no Brasil, o consumo de frutas se mostra abaixo do recomendado por organizações especializadas. O consumo mínimo recomendado é de $400 \mathrm{~g}$ de frutas e hortaliças diariamente, como comportamento promotor de saúde e fator de proteção para diversas doenças crônicas (Who, 2003; Brasil, 2014). Amostragem realizada pela Vigitel Brasil (2019), em todas as capitais do Brasil, foi demonstrado que somente $23,1 \%$ dos entrevistados atingem a frequência de consumo recomendada de frutas e hortaliças, sendo menor entre os homens (18,4\%), quando comparada às mulheres $(27,2 \%)$. A constância do consumo recomendado de frutas e hortaliças tendeu a aumentar com a idade entre mulheres até os 64 anos, não havendo um padrão uniforme de variação com a idade no caso dos homens (Vigitel Brasil, 2019).

É importante a identificação dos motivos pelos quais a maioria da população não atinge a frequência mínima de consumo de frutas. Para Teixeira (2013) a população frequentemente associa à prática alimentar saudável à saúde e ao consumo de frutas e hortaliças, mas, devido a diferentes fatores como o preço, a falta de tempo para as refeições, dificuldades financeiras, questões relacionadas ao sabor e a hábitos culturais, acaba por fazer escolhas menos saudáveis.

Entender o processo de escolha no momento da compra pelos consumidores, tem se constituído em preocupação constante das empresas, que buscam cada vez mais, desenvolver produtos e serviços que estejam em concordância com os desejos dos seus clientes, tanto os atuais, como potenciais (Rosa Neto et al., 2006). Nos comércios varejistas de frutas, a não satisfação do consumidor significa desperdício de produtos, ocasionando perda na lucratividade, fato que poderia ser resolvido com cuidados básicos, que vão desde o transporte, até a exposição adequada das frutas nas gôndolas. No Brasil, as perdas no segmento de frutas e hortaliças, atingem em média 30\% e 35\%, respectivamente (Zaro, 2018). Dentre as principais causas destaca-se o manuseio inadequado no campo, classificação não padronizada, comercialização de produtos a granel, embalagens impróprias, veículos supercarregados, estradas deficientes, excesso de "toque" nos produtos por parte dos consumidores e o acúmulo de produtos nas gôndolas de exposição no varejo (Zaro, 2018).

Estudos sobre o hábito do consumi $\neg$ dor são fundamentais para compreender suas demandas, permitindo que todos os integrantes dos sistemas agroalimentares adaptem suas estratégias (Perosa et al., 2012). Os mesmos autores obtiveram resultados sobre o perfil do consumidor de frutas nas cidades de Botucatu, Avaré, Jaboticabal, Ilha Solteira e Tupã no Estado de São Paulo, e constataram que os consumidores sinalizaram uma preocupação com as características do produto (saudáveis e saborosos), com o preço e com facilidades de acesso 
na compra. Da mesma forma, Alves et al. (2014) analisaram o perfil dos consumidores de frutas do complexo Ver-o-Peso em Belém no Pará, e constataram que a compra no local é motivada pelo preço baixo e variedade de produtos.

Souza (2014) analisou a agricultura familiar da cidade de Barra-BA, e verificou a exploração de banana, caju, laranja, manga, coco, cana-de-açúcar, feijão, mandioca, milho, melancia, dentre outras culturas, porém, são poucos hectares explorados e o incentivo de políticas públicas são mínimas, impondo entraves à produtividade da agricultura local, sendo na maioria das vezes absorvidos pela própria família. A cidade também dispõe de feira livre, sacolões e supermercados que ofertam frutas, sendo de suma importância para comerciantes e consumidores. Estudos dessa natureza se mostram importantes para identificar o comportamento dos consumidores, bem como suas dificuldades, preferências e sua percepção sobre o comércio local. Em relação aos comerciantes, conhecer o perfil do consumidor pode ser de grande relevância para definição de estratégias mais adequadas para o incentivo ao consumo, e a sua própria melhoria e do seu comércio.

Pesquisas relacionadas ao consumo e comércio de frutas da cidade são escassas, neste sentido, objetivou-se neste trabalho, identificar o perfil dos consumidores e dos comerciantes de frutas da cidade de Barra-BA, de forma a gerar dados informativos acerca do comércio e consumo de frutas, com vista a proposição de melhorias e exploração de novos nichos do mercado de frutas da cidade.

\section{Material e Métodos}

Essa pesquisa foi direcionada a avaliação do perfil dos consumidores e comerciantes de frutas do município de Barra, localizado no oeste do Estado da Bahia (coordenadas $11^{\circ} 5^{\prime}$ 20" S, 43 $8^{\prime}$ 31" W), com população estimada em 53.578 habitantes (IBGE, 2019). Empregou-se a técnica de pesquisa por comunicação direta com os entrevistados, por meio de questionários socioeconômicos estruturados e padronizados, incluindo questões abertas e fechadas, sendo aplicado no comércio varejista de frutas e feiras livres da cidade, tendo como público alvo os consumidores presentes nestes locais no momento das entrevistas e os proprietários destes estabelecimentos. Os questionários foram planejados de forma a coletar informações referentes à hábitos de consumos, formas de comercialização de frutas, bem como a caracterização socioeconômica de comerciantes e consumidores de frutas. A coleta dos dados foi realizada no decorrer dos meses de setembro e outubro de 2019. Para que a obtenção dos dados fosse a mais fiel possível da realidade, as entrevistas foram realizadas nos 
dias e horários que se costuma ter uma maior concentração de consumidores no comércio de frutas da cidade. Na feira livre, as entrevistas foram realizadas nos finais de tarde das quintasfeiras e manhãs das sextas-feiras, nos sacolões e supermercados as entrevistas foram realizadas nos dias de terças-feiras pela manhã e finais de tarde.

O questionário foi composto pelas seguintes questões para os consumidores: 1 - Sexo; 2 - Faixa etária; 3 - Nível de escolaridade; 4 - Ocupação/profissão; 5 - Qual frequência que compra frutas; 6 - Em quais locais, costuma adquirir frutas; 7 - Por que compra nesse estabelecimento; 8 - Quanto gasta, em média, com frutas por compra; 9 - Frutas que costuma comprar; 10 - Frutas que não encontram no mercado e desejaria adquirir; 11 Compraria/consumiria uma fruta diferentes/desconhecida; 12 - Sobre a qualidade das frutas adquiridas; 13 - Qual(is) principais defeitos encontrados nas frutas nos locais que costuma comprar; 14 - O que precisa mudar para atender a qualidade desejada.

As questões direcionadas aos comerciantes constituíram-se das seguintes: 1 - Sexo; 2 Faixa etária; 3 - Nível de escolaridade; 4 - Há quanto tempo trabalha com venda de frutas; 5 Produz alguma fruta que comercializa; 6 - Quais frutas produz e comercializa; 7 - Onde adquire as frutas que comercializa; 8 - Porque não compra frutas produzidas no município? Como manga, banana, etc; 9 - Como é a forma de embalagens para transporte das frutas; 10 Veículo para transporte das frutas; 11 - Quais as dificuldades que encontra para comercializar frutas; 12 - Qual o tempo médio (dias) a fruta permanece na prateleira para venda; 13 - Tem perdas pós-colheita das frutas; 14 - Quanto em \%; 15 - O que faz para reduzir as perdas.

A amostra foi constituída por 200 consumidores, selecionados de forma aleatória, por estarem frequentando o local de comércio de frutas no momento da aplicação dos questionários. Para os estabelecimentos, fez-se um levantamento de todos os comércios varejistas de frutas, totalizando 41 amostras, constituídas por sacolões, barracas da feira livre e supermercados na zona urbana do município.

Os dados obtidos com a aplicação dos questionários foram tabulados no software Microsoft Excel, sendo consideradas como variáveis cada uma das questões fechadas, bem como as abertas, e os resultados expressos em frequência relativa. Assim, a frequência simples foi usada como base de cálculo das frequências relativas, sendo submetidas a estatística descritiva e sistematizados em gráficos e tabelas. 


\section{Perfil dos Consumidores de Frutas}

Em relação aos consumidores entrevistados, verificou-se que $60,5 \%$ dos entrevistados são representados pelo sexo feminino (Tabela 1). Resultados semelhantes foram encontrados no estudo de Rosa Neto et al. (2006), em que se constataram que as mulheres são as principais compradoras de frutas nos supermercados e feiras livres nas cidades de Porto Velho, Cacoal, Ji-Paraná e Ouro Preto, no estado de Rondônia. Para Silva e Costa (2011) as mulheres são as principais responsáveis pela tomada de decisão de compra, além de se demonstrarem atenciosas aos detalhes na escolha do produto.

No tocante a idade, $45 \%$ dos consumidores estão com 20 a 35 anos, seguido de consumidores de 36 a 50 anos com 24\%. Consumidores de 51 a 60 anos e maiores de 60 anos, são minoria no comércio de frutas da cidade (Tabela 1). Guerra et al. (2018) também constataram a menor presença do consumidor de maior idade na feira livre de Barra-BA, e relataram que o não comparecimento destes a feira, não impede que seus recursos sejam usados na compra de frutas e verduras. A maior presença de consumidores com idade entre 20 a 35 anos pode ser associada a crescente público universitário na cidade, visto que quando observado o nível de escolaridade dos entrevistados, 53,5\% afirmam terem concluído o ensino médio, e quanto a ocupação/profissão, estudantes consumidores são maioria entre os entrevistados, representando 32\% (Tabela 1). Na maioria das vezes, os universitários por morarem sozinhos, são responsáveis pelas compras e na maioria dos casos, preparo das refeições.

Tabela 1 - Frequência relativa do perfil socioeconômico de consumidores de frutas nos comércios e feiras livres da cidade de Barra-BA.

\begin{tabular}{lc}
\hline Sexo & $\%$ \\
\hline Feminino & 60,5 \\
Masculino & 39,5 \\
\hline Faixa etária & \\
\hline$<20$ anos & 15,5 \\
$20-35$ anos & 45,0 \\
$36-50$ anos & 24,0 \\
$51-60$ anos & 9,0 \\
$>60$ anos & 6,5 \\
\hline
\end{tabular}

Nível de escolaridade 
Analfabeto

Fundamental

Médio

Superior

Técnico profissionalizante

Ocupação/profissão

Estudante

Doméstica

Funcionário

Autônomo

Aposentado

Agricultor

Pescador

Frequência que compra frutas

Todos os dias

Semanal

Quinzenal

Locais que costuma adquirir frutas

Sacolão

Supermercado

Feira

Gasto, em média, com frutas por compra

R\$ $10-20$

$\mathrm{R} \$ 21-30$

$\mathrm{R} \$ 31-50$

$>\mathrm{R} \$ 50$

Fonte: Autoria própria (2020).

Em relação à frequência de compra de frutas, 62,5\% dos consumidores afirmam realizarem compras semanalmente, $29,5 \%$ compram quinzenalmente e $8 \%$ compram todos os dias (Tabela 1). A frequência de compras pode ser motivada pela logística dos comerciantes da cidade, que costumam comprar frutas somente uma vez por semana, em função da logística de transporte presente no município, levando os consumidores a irem às compras motivados pela presença de frutas frescas e de melhor qualidade apenas no dia da oferta.

A maioria dos entrevistados, 36\%, gasta em média de $\mathrm{R} \$ 21$ a 30 por compra de frutas, $28 \%$ gastam em média de $\mathrm{R} \$ 10$ a 20, 26\% gastam de $\mathrm{R} \$ 31$ a 50 por compra (Tabela 
1). Ao considerar que a maioria dos consumidores compram frutas semanalmente, observa-se consumo de frutas relativamente baixo entre os entrevistados, o motivo pode estar relacionado ao fato de muitas frutas serem perecíveis em curto prazo, ou também ao fator renda, o que conduz o consumidor a comprar menores quantidades. Ademais, a facilidade de acesso aos locais de comercialização pode justificar a compra de menor quantidade por vez.

Os sacolões se destacam como local de preferência para compra de frutas com $51 \%$ citando como local preferido, seguido da feira livre com $36 \%$ e supermercados com $13 \%$ (Tabela 1). A preferência pelos sacolões também pode ser observada por consumidores de hortaliças da cidade de Barra-BA, como verificado por Guerra et al. (2018). Os sacolões dispõem de ambiente geralmente climatizado e uma variedade de frutas, além disso, estão presentes em toda cidade, facilitando o acesso do consumidor. São diversos os motivos dos consumidores fazerem suas compras de frutas nos sacolões, para 23,9\% dos entrevistados, os motivos se devem a proximidade de sua residência, já para $21,1 \%$, o preço e $13,8 \%$ atestam a maior qualidade de produtos nos sacolões (Tabela 2). A feira livre está presente no centro da cidade, também conta com uma variedade de produtos, porém, o ambiente muitas vezes desorganizado e mal estruturado e as questões de higiene, podem levar o consumidor a procurar outras opções de locais de compras. O preço (39\%) e proximidade (32,5\%) são os principais motivos pela compra na feira, porém, de acordo com as observações do consumidor, deixa a desejar em qualidade, ambiente, higiene e atendimento em relação aos outros estabelecimentos, necessitando de melhorias estruturais com vistas a atender os consumidores, pois apresenta preço mais baixo em relação aos demais locais de comercialização, provavelmente pelos feirantes não terem tantas despesas como sacolões e supermercados, que pagam por aluguel, água, energia elétrica, dentre outras despesas, que podem influenciar no preço final dos produtos. A baixa frequência de consumidores nos supermercados pode ter relação com o baixo número destes estabelecimentos ofertando frutas com qualidade aceitável, além de poucas variedades. A oferta de frutas em supermercados da cidade é bem recente, o consumidor pode não ter ainda adquirido esse hábito de compras de frutas neste tipo de estabelecimento. O preço acessível, proximidade das residências e variedade de produtos, são os motivos pela compra com 18,5\% cada. 
Research, Society and Development, v. 9, n. 8, e947985532, 2020

(CC BY 4.0) | ISSN 2525-3409 | DOI: http://dx.doi.org/10.33448/rsd-v9i8.5532

Tabela 2 - Principais motivos dos consumidores pela compra de frutas em sacolões, supermercados e feira livre da cidade de Barra-BA.

\begin{tabular}{lccc}
\hline Motivo & Sacolão $(\boldsymbol{\%})$ & Supermercado $(\boldsymbol{\%})$ & Feira $(\boldsymbol{\%})$ \\
\hline Preço & 21,1 & 18,5 & 39,0 \\
Proximidade & 23,9 & 18,5 & 32,5 \\
Variedades de produtos & 12,0 & 18,5 & 10,4 \\
Qualidade & 13,8 & 14,8 & 7,8 \\
Ambiente & 12,0 & 14,8 & 5,2 \\
Higiene & 12,0 & 7,4 & 1,3 \\
Atendimento & 5,5 & 7,4 & 3,9 \\
\hline Total & $\mathbf{1 0 0}$ & $\mathbf{1 0 0}$ & $\mathbf{1 0 0}$ \\
\hline
\end{tabular}

Fonte: Autoria própria (2020).

Em relação à qualidade das frutas, $60 \%$ dos consumidores afirmam que atendem a suas exigências parcialmente, $36 \%$ atestam que a qualidade atende e $4 \%$ dizem que não atende (Tabela 3). A qualidade é uma característica imprescindível na hora da compra, o consumidor está cada vez mais exigente e sempre busca por melhores frutas, com aspecto visual adequado, livre de doenças ou ataques de pragas, e esse pode ser um ponto a ser considerado na hora da decisão do local de compra. Quanto aos principais defeitos encontrados nas frutas, os mais citados foram amassamento, murcha e podridão com 27,2\%, 26 e 18,3\%, respectivamente (Tabela 3). Devido à logística de aquisição de frutas em cidades vizinhas, a cerca de $200 \mathrm{~km}$, o principal motivo pelos danos pode estar relacionado a embalagem e ao transporte inadequado.

Tabela 3 - Porcentagem da opinião dos consumidores sobre a qualidade das frutas e os principais defeitos encontrados.

\begin{tabular}{lc}
\hline Qualidade das frutas adquiridas & 36,0 \\
\hline Atende & 60,0 \\
Atende parcialmente & 4,0 \\
Não atende & \\
\hline Principais defeitos encontrados nas frutas & 26,0 \\
\hline Murcha & 18,3 \\
Podridão & 7,6 \\
Cortes & 27,2 \\
Amassado & 12,2 \\
Coloração inadequada & 8,7 \\
\hline Imaturo
\end{tabular}

Fonte: Autoria própria (2020). 
Research, Society and Development, v. 9, n. 8, e947985532, 2020

(CC BY 4.0) | ISSN 2525-3409 | DOI: http://dx.doi.org/10.33448/rsd-v9i8.5532

As principais frutas adquiridas pelos entrevistados na cidade de Barra-BA estão representadas na Figura 1. A banana é a favorita dos consumidores, com $82 \%$ da preferência, seguida pela maçã e laranja com 70,5 e 68,5 \%, respectivamente. Resultados semelhantes foram observados por Alves et al. (2014) e Perosa et al. (2012), que apontaram as razões para o maior consumo dessas frutas. Segundo eles, a oferta destas frutas durante todo o ano, os preços acessíveis, a praticidade para o consumo individual e a facilidade de acesso, podem ser os principais motivos que levam a preferência pelo consumo dessas frutas.

Figura 1 - Percentual das principais frutas adquiridas pelos consumidores da cidade de BarraBA.

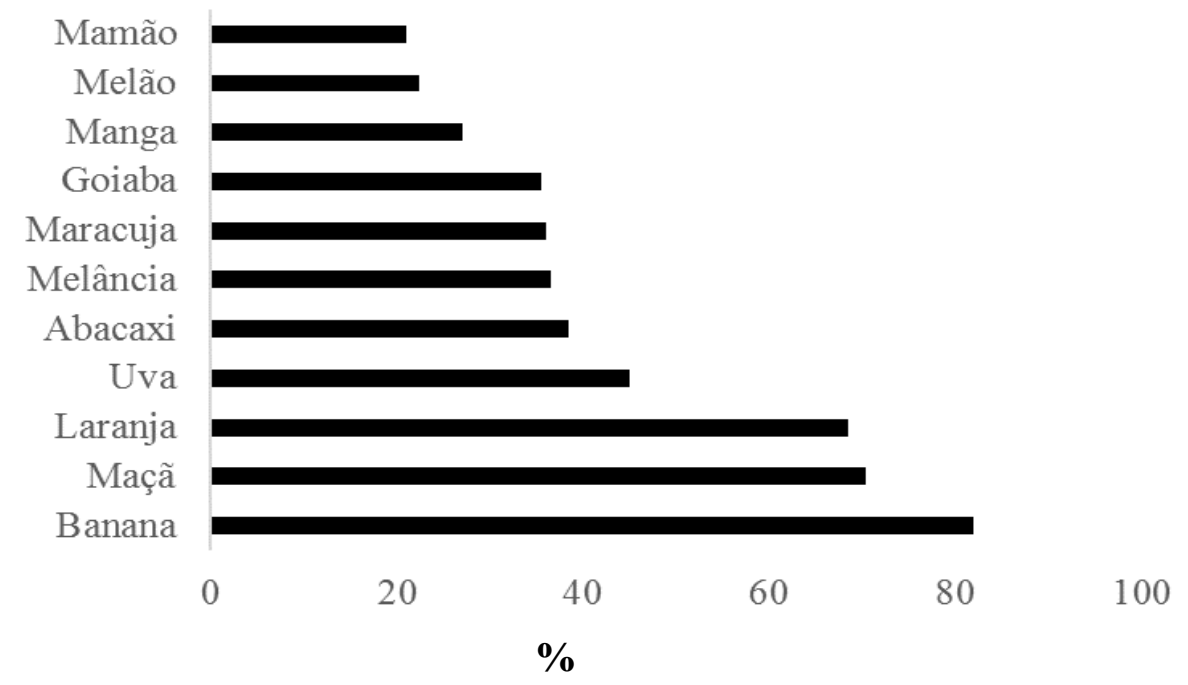

Fonte: Autoria própria (2020).

Ao serem questionados sobre a intenção de compra ou consumo de frutas diferentes ou desconhecidas, $62 \%$ disseram que sim, sendo o maior motivo a curiosidade de provar uma fruta diferente com 30,6\%. Já $28,2 \%$ citaram o sabor e 4,8\% citaram que consumiria se comprovado o valor nutricional da fruta. $38 \%$ dos entrevistados responderam que não, por desconhecimento sobre outras frutas, não tendo nenhuma informação sobre ela ou sobre sua procedência. O desconhecimento sobre determinadas frutas, pode leva-lo a dúvida, sobretudo, sobre os benefícios ou malefícios à saúde.

Quando questionados sobre determinada fruta que não encontram no mercado da cidade e desejariam adquirir, 56,5\% dos entrevistados apontam que não encontram todas as frutas que desejam adquirir, já 43,5\% dos entrevistados responderam que encontram todas as frutas que desejam. Para aqueles que não encontram todas as frutas, $20 \%$ citam a jabuticaba, 
Research, Society and Development, v. 9, n. 8, e947985532, 2020

(CC BY 4.0) | ISSN 2525-3409 | DOI: http://dx.doi.org/10.33448/rsd-v9i8.5532

em seguida o morango com $19 \%$, jaca com $17 \%$ e pinha com $15 \%$, como as frutas que desejariam adquirir (Figura 2).

Figura 2 - Percentual das principais frutas não encontradas no mercado pelos consumidores da cidade de Barra-BA.

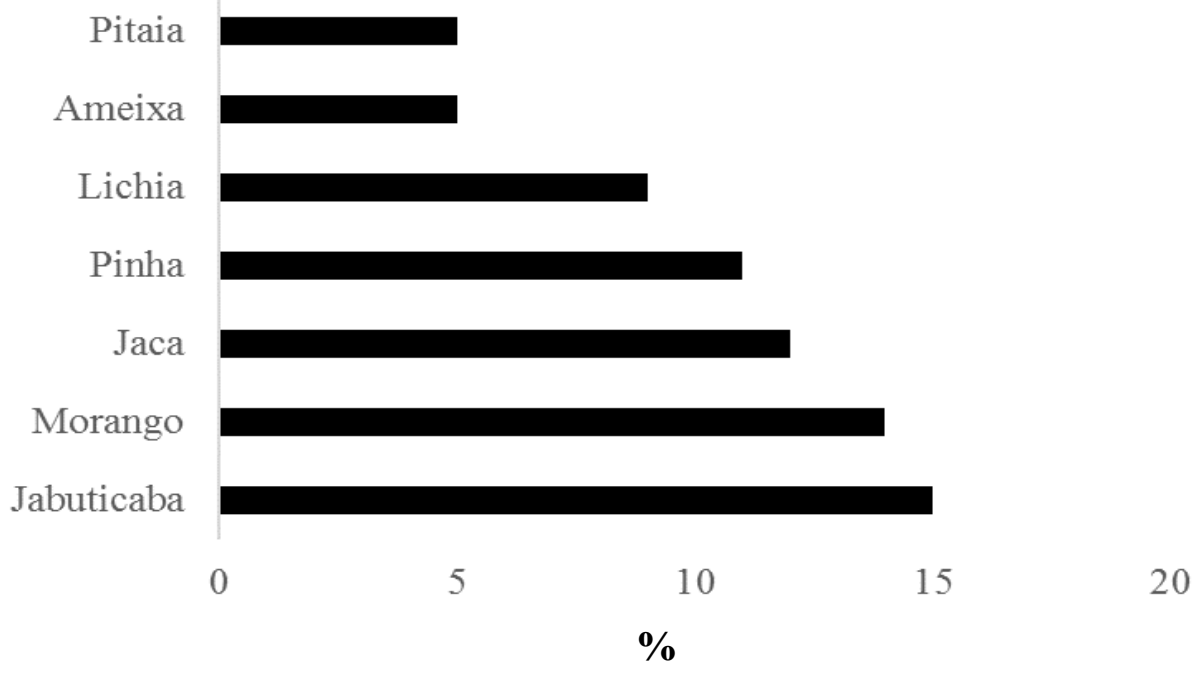

Fonte: Autoria própria (2020).

A jabuticaba também é a fruta mais citada quando se questionou sobre a compra de frutas diferentes ou desconhecidas com 25\% (Figura 3), mostrando que tem mercado para ser explorada na cidade. Observa-se também um potencial para o crescimento de novas frutas para o mercado como a pitaia e a lichia. O comércio da cidade conta com uma grande variedade de frutas, podendo atender a demanda dos consumidores por frutas mais consumidas, porém, algumas frutas pouco consumidas são ofertadas em pequenas quantidades, provavelmente devido ao maior preço dessas frutas e serem bastante perecíveis, os comerciantes prefiram a compra para revenda em pequenas quantidades, podendo em alguns casos, ter uma demanda maior do que o esperado. 
Research, Society and Development, v. 9, n. 8, e947985532, 2020

(CC BY 4.0) | ISSN 2525-3409 | DOI: http://dx.doi.org/10.33448/rsd-v9i8.5532

Figura 3 - Percentual das frutas diferentes ou desconhecida que os consumidores da cidade de Barra-BA consumiriam.

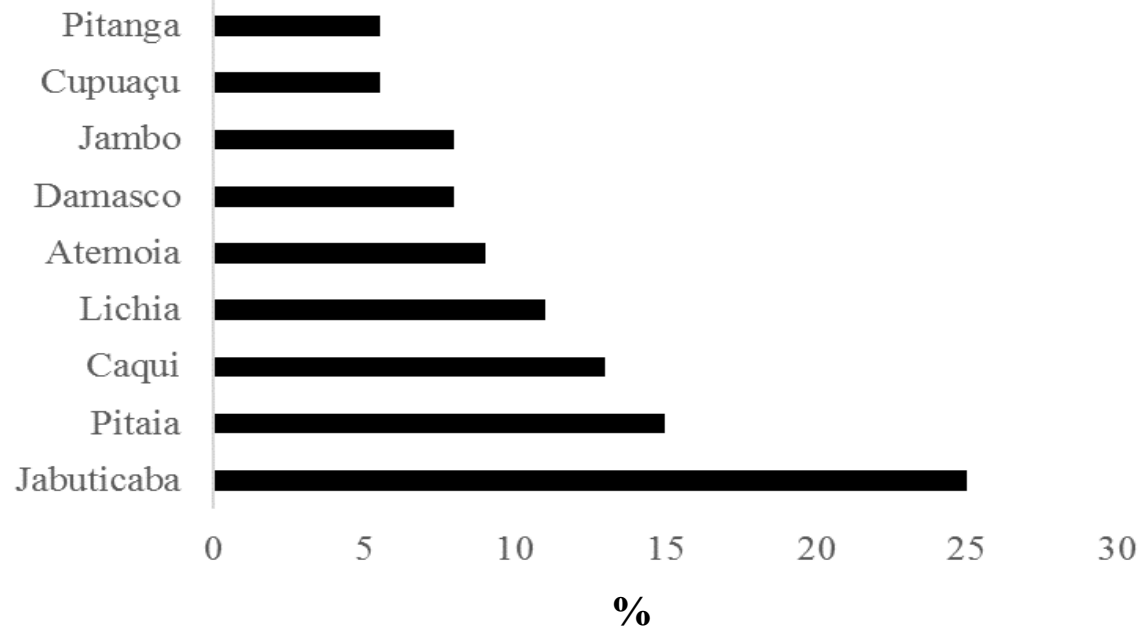

Fonte: Autoria própria (2020).

Em relação às necessidades de mudança nos comércios para atender ao padrão de qualidade de frutas que se deseja, 24,7\% citam que precisa de melhoria no armazenamento e refrigeração das frutas, $23,5 \%$ citam que deve se ter maior cuidado no transporte e manuseio das frutas, 20,3\% propõem que deve se melhorar a qualidade da fruta a ser ofertada, 14,3\% acham que ofertar mais frutas e com preços acessíveis seria uma boa mudança (Figura 4).

Figura 4 - Opinião dos consumidores acerca das mudanças nos comércios para atender a qualidade de frutas desejada na cidade de Barra-BA.

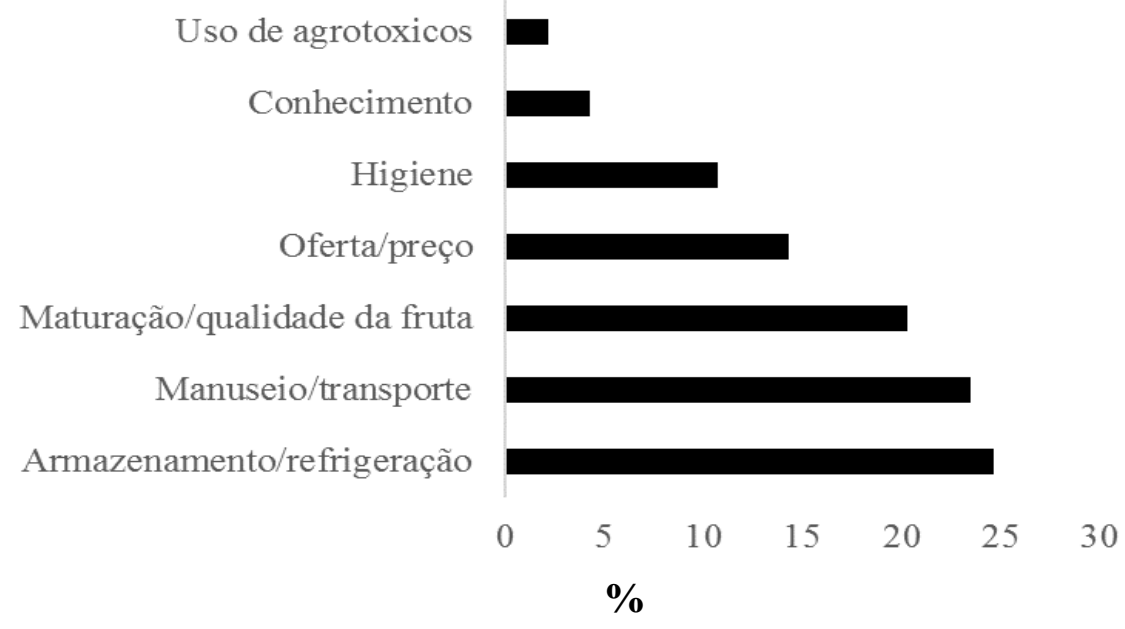

Fonte: Autoria própria (2020).

Os dados mostram que os consumidores apresentam conhecimento acerca da situação dos estabelecimentos comerciais da cidade, fato que pode levar a influenciar na escolha do 
local para compras, sendo muito importante para que os comerciantes se adequem às necessidades apontadas pelos consumidores, a fim de ofertar produtos de qualidade.

\section{Perfil dos Comerciantes de Frutas}

Quanto aos comerciantes, dos 41 estabelecimentos pesquisados (19 sacolões, 16 barracas da feira livre e 6 supermercados), nota-se a maior presença do sexo masculino, representando 60,9\% dos comerciantes (Tabela 4). A maior parte dos comerciantes encontrase na faixa etária de 20 a 35 anos, representando $51,2 \%$, outros $22 \%$ estão na faixa de 36 a 50 anos. Quanto à escolaridade, 65,8\% possui ensino médio, $22 \%$ ensino fundamental e 7,4\% são analfabetos, apenas 4,8\% possuem nível superior (Tabela 4). Muitos comerciantes, principalmente feirantes, possuem baixo grau de instrução, provavelmente pelo motivo de ter que trabalhar muito jovem para ajudar a família, praticamente deixando os estudos em segundo plano.

Quanto a experiência no comércio de frutas, 51,2\% possuem menos de 5 anos na atividade, $31,8 \%$ trabalham com frutas de 5 a 10 anos, 4,8\% já trabalham de 11 a 15 anos e $12,2 \%$ trabalham com frutas a mais de 15 anos (Tabela 4). A crescente chegada de estudantes universitários nos últimos cinco anos na cidade, pode ter influenciado o maior percentual de comércios de frutas recentes na cidade, no intuído de atender a esse público recente. Salientase, no entanto, que em alguns estabelecimentos não foi encontrado a presença do proprietário, sendo entrevistados os funcionários responsáveis pelo comércio, em sua maioria, jovens, o que também pode retratar os resultados obtidos.

Em relação ao questionamento sobre a produção de frutas que comercializam, 97,5\% dos comerciantes afirmam que não produzem nenhuma fruta, apenas $2,5 \%$ produz em pequena escala, coco verde, limão e manga, de modo convencional, para comercialização na feira livre (Tabela 4). O município de Barra apresenta grande potencial para agricultura, porém ainda pouco explorado por diversos motivos, como falta de infraestrutura de investimento, apoio técnico extensionista governamental, além de pouco conhecimento para investir na atividade de produção frutícola, em geral, a agricultura praticada é de subsistência, produzido em pequena escala coco verde, limão, manga, mamão e melancia, que são utilizados para o próprio consumo ou venda na feira livre da cidade. 
Research, Society and Development, v. 9, n. 8, e947985532, 2020

(CC BY 4.0) | ISSN 2525-3409 | DOI: http://dx.doi.org/10.33448/rsd-v9i8.5532

Tabela 4 - Distribuição de frequência percentual de comerciantes de frutas em Barra-BA.

\begin{tabular}{lc}
\hline Sexo & $\%$ \\
\hline Feminino & 39,1 \\
\hline Masculino & 60,9 \\
\hline Faixa etária & \\
\hline$<20$ anos & 7,3 \\
$20-35$ anos & 51,2 \\
$36-50$ anos & 22,0 \\
51 - 60 anos & 17,0 \\
$>60$ anos & 2,5 \\
\hline Nível de escolaridade & 7,4 \\
\hline Analfabeto & 22,0 \\
Fundamental & 65,8 \\
\hline Médio & 4,8 \\
\hline Superior & 4,8 \\
\hline Tempo que trabalha com venda de frutas & \\
\hline 11 a 15 anos & 51,2 \\
\hline Pro anos & 31,8 \\
\hline
\end{tabular}

\section{Produz alguma fruta que comercializa?}

Sim

Não

Porque não compra frutas produzidas no município?

Não Encontra

Compra na época de produção

Preço

Oferta insuficiente

Não tem interesse 
Dificuldades que encontra para comercializar frutas

Não encontra

Concorrência

Crise Financeira

Logística

Falta de um CEASA

Fonte: Autoria própria (2020).

Em outro questionamento sobre o motivo de não comprar frutas no município, 60,4\% afirmam que não encontram frutas disponíveis na cidade, 20,3\% dizem que compram em épocas de ofertas de algumas frutas que são produzidas no município, 10,1\% dizem que não compra pois o preço é elevado, sendo mais compensatório comprar em cidades vizinhas, 4,6\% afirmam que a oferta de frutas na cidade é insuficiente para atender a demanda, outros 4,6\% dizem não ter interesse na compra de frutas locais e afirmam que os próprios produtores da cidade também não tem esse interesse em produzir frutas para comercialização (Tabela 4), o que é um problema a ser resolvido, já que o município apresenta potencial hídrico, condições edafoclimáticas adequadas e mão de obra disponível para produção frutícola.

Ao se questionar aos comerciantes sobre quais as dificuldades encontram para comercializar frutas, 48,8\% afirmam que não tem dificuldades na comercialização, já 29,3\% citam a concorrência e 14,7\% dizem que a crise financeira é um dos fatores mais limitantes, em função da redução no volume de compras de seus clientes. $4,8 \%$ têm dificuldades devido à logística de transporte que se tem desde o produtor até a chegada em suas prateleiras, pois grande parte das frutas comercializadas são oriundas de outras cidades. A falta de um centro de abastecimento na cidade prejudica a comercialização de frutas, a presença facilitaria a compra de frutas com melhor qualidade, menor preço e com maior frequência, ao invés de ser semanal, como ocorre atualmente (Tabela 4).

Em relação a localidade onde os comerciantes de Barra-BA adquirem as frutas, a Figura 5 mostra que a cidade de Irecê-BA, localizada a cerca de $200 \mathrm{~km}$, é a principal fornecedora, com 92,6\%. A cidade de Juazeiro-BA é citada por 12,1\% dos comerciantes, porém segundo relatos dos mesmos, a maioria das frutas encontradas em Irecê, são oriundas de Juazeiro-BA. Ibotirama-BA é citado por $2,4 \%$ dos comerciantes como fornecedor de banana e Gentil do Ouro-BA é citado na mesma proporção como fornecedor de maracujáamarelo. De acordo com Guerra et al. (2018) Irecê também é a principal fornecedora de 
Research, Society and Development, v. 9, n. 8, e947985532, 2020

(CC BY 4.0) | ISSN 2525-3409 | DOI: http://dx.doi.org/10.33448/rsd-v9i8.5532

hortaliças para comercialização na cidade, em função de apresentar centro de distribuição mais próximo.

Figura 5 - Principais localidades onde os comerciantes de Barra-BA adquirem frutas para comercialização.

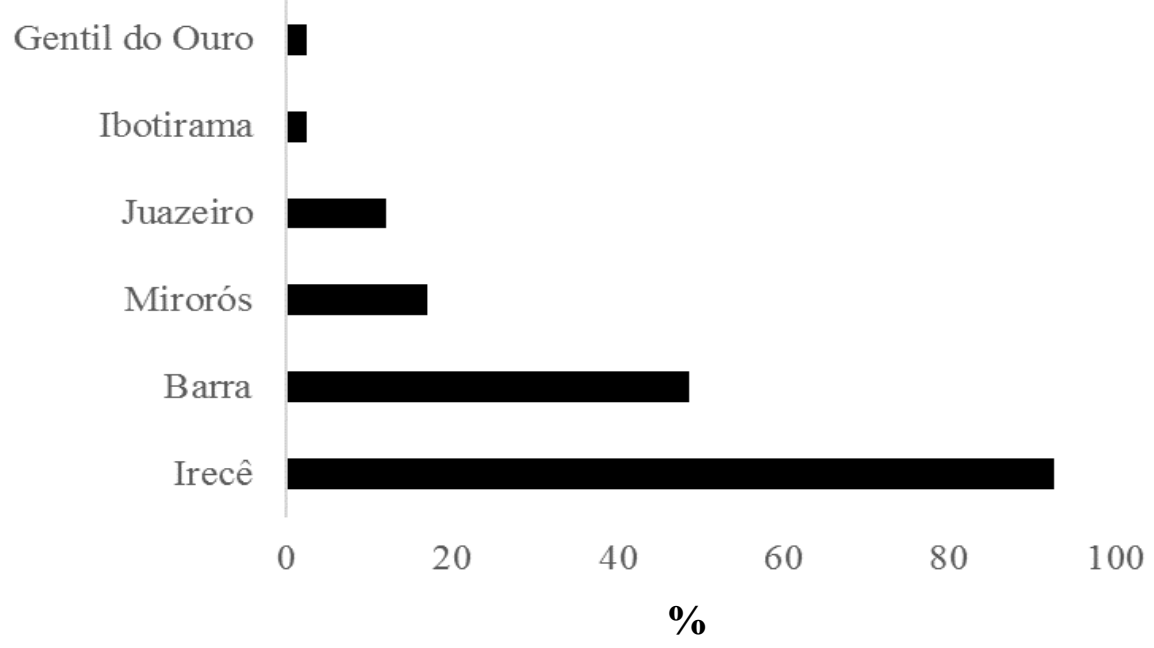

Fonte: Autoria própria (2020).

Em relação às embalagens utilizadas no transporte das frutas, verifica-se que $63,5 \%$ usam contentores plásticos, 26,9\% utilizam tipos variados de embalagem como contentores plásticos, caixas de papelão e sacos plásticos (Tabela 5). Contentores plásticos são uma boa opção para esse fim, possibilitando a higienização dessas embalagens para retorno, minimizando danos mecânico, sendo também utilizado para o acondicionamento dos produtos antes de serem expostos nas bancas. Observa-se que poucos varejistas usam caixas de madeira, esse tipo de embalagem pode causar danos às frutas. A unidade de transporte das frutas mais utilizada são os caminhões baú fechado sem refrigeração e caminhões com carroceria aberta com $46,4 \%$ e $43,9 \%$, respectivamente. $7,3 \%$ utilizam veículo próprio. $\mathrm{O}$ caminhão baú fechado refrigerado é usado por apenas $2,4 \%$, o que seria a unidade de transporte mais apropriado para as frutas (Tabela 5). $\mathrm{O}$ transporte sem um acondicionamento adequado pode causar danos mecânicos as frutas como amassamentos, quedas ou batidas advindas do empilhamento de caixotes com frutas acima da capacidade ou por pressão das primeiras camadas de frutas, as abrasões ou vibrações podem resultar em machucaduras, quando o produto vibra ou se move contra superfícies ásperas durante o transporte, chegando ao destino final já com sua qualidade comprometida (Marques \& Caixeta Filho, 2000). 
Tabela 5 - Porcentagem de embalagens e unidade de transporte utilizadas pelos comerciantes de frutas de Barra-BA.

\begin{tabular}{lc}
\hline Formas de embalagens para transporte das frutas & \\
\hline Caixa papelão & 4,8 \\
Caixa madeira & 2,4 \\
Caixa plástica & 63,5 \\
Sacos & 2,4 \\
Variados & 26,9 \\
\hline Unidade de transporte das frutas & \\
\hline Baú refrigerado & 2,4 \\
Baú fechado & 46,4 \\
Carroceria aberta & 43,9 \\
Outro & 7,3 \\
\hline
\end{tabular}

Fonte: Autoria própria (2020).

A perda pós-colheita é unânime entre os comerciantes, e quando questionados sobre o que fazem para minimizar estas perdas, 37,2\% não fazem nada, por desconhecimento sobre como proceder, ou não dispõe de recursos financeiros para instalações apropriadas. Dos que fazem alguma ação no sentido de evitar perdas, 31,5\% relatam que utilizam climatizadores de ar que são mais presentes em sacolões e supermercados. $11,7 \%$ relatam a realização de promoções para venda mais rápida das frutas, $9,8 \%$ dos comerciantes compram quantidades limitadas de frutas para não ter prejuízos e 9,8\% citam realizar a higiene do local, retirando frutas estragadas e fazendo limpezas diárias das prateleiras (Tabela 6). Indagou-se aos comerciantes o que era feito com as perdas, e quase em sua totalidade, as perdas eram doadas para criadores de animais como porcos e galinhas. Resultados semelhantes foram obtidos por Guerra et al. (2018) na cadeia de hortaliças na mesma cidade. De acordo com Freitas-Silva et al. (2013) as frutas e hortaliças são altamente perecíveis devido ao alto teor de água em sua composição química, consequentemente apresentam uma vida pós-colheita curta. Para que o tempo de conservação seja maximizado e ocorra a redução de perdas durante a pós-colheita mantendo-as conservadas para um maior tempo de consumo, é importante que conheça e utilize as práticas adequadas de manuseio desde as fases de colheita até a comercialização e consumo. 
Research, Society and Development, v. 9, n. 8, e947985532, 2020

(CC BY 4.0) | ISSN 2525-3409 | DOI: http://dx.doi.org/10.33448/rsd-v9i8.5532

Tabela 6 - Porcentagem de perdas pós-colheita no comércio de frutas de Barra-BA e ações dos comerciantes para minimiza-las.

\begin{tabular}{lc}
\hline Tem perdas pós-colheita das frutas? & \\
\hline Sim & 100 \\
Não & 0,0 \\
\hline O que faz para reduzir as perdas? & \\
\hline Nada & 37,2 \\
Usa climatizador & 31,5 \\
Limita as compras de frutas & 9,8 \\
Faz higienes do local & 9,8 \\
Realiza promoções & 11,7 \\
\hline
\end{tabular}

Fonte: Autoria própria (2020).

De acordo com os comerciantes, o tempo médio que a fruta permanece na prateleira para venda varia de 2 a 7 dias (Tabela 7). A banana como é a fruta mais vendida, fica por um curto período, de 2 a 3 dias e a perda varia de 5 a 10\%. De acordo com relato dos comerciantes, a maioria das frutas ficam até 1 semana na prateleira, até a renovação que acontece toda semana.

Tabela 7 - Tempo médio que a fruta permanece na prateleira dos comerciantes para venda e porcentagem de perdas das frutas.

\begin{tabular}{lcc}
\hline Fruta & Tempo (dias) & Perdas (\%) \\
\hline Abacaxi & 5 & 10 \\
Banana & 2 a 3 & 5 a 10 \\
Goiaba & 5 & 10 a 20 \\
Laranja & 5 & 10 a 20 \\
Maçã & 5 & 10 a 20 \\
Mamão & 7 & 10 a 20 \\
Uva & 5 & 10 \\
\hline
\end{tabular}

Fonte: Autoria própria (2020).

Dessa maneira, percebe-se que as frutas com maior índice de perdas são a goiaba, laranja, maçã e mamão, variando de 10 a 20\%. Esses resultados podem ser explicados devido ao alto volume comercializado dessas frutas, às vezes maiores que a demanda possa absorver, e acaba sobrando nas prateleiras, sendo alimentos perecíveis, acaba resultando em perdas destas frutas. 


\section{Considerações Finais}

A maioria do público consumidor de frutas da cidade é constituída pelo gênero feminino, e sua frequência de compras é influenciada pela logística dos comerciantes que costumam renovar as prateleiras apenas vez por semana. Fatores como o preço baixo, proximidade da residência e variedades de produtos são levados em conta na escolha do local para compra de frutas.

A cidade tem potencial para exploração do comércio de frutas como a jabuticaba, frutas da região como jaca e pinha e frutas exóticas como pitaia e lichia.

Um dos grandes problemas do comercio local é a desvalorização da própria produção de frutas da cidade, sempre obtendo frutas para revenda em cidades vizinhas, sendo sujeita a danos com o transporte inadequado.

A feira livre é um importante ponto comercial tanto para comerciantes como para pequenos produtores, investimentos em sua infraestrutura, bem como organização e higiene do local pode torna-la mais bem frequentada pela população, contribuindo ainda mais para movimentação econômica da cidade.

\section{Referências}

Alves, R. J. M., Souza, L. P. F., \& Pontes, A. N. Perfil socioeconômico e satisfação dos consumidores de produtos hortifrutícolas do complexo do Ver-O-Peso, Pará. Enciclopédia Biosfera, Centro Científico Conhecer - Goiânia, 10919), 2912. 2014.

Brasil. Ministério da Saúde. Secretaria de Atenção à Saúde. Departamento de Atenção Básica. Guia alimentar para a população brasileira. (2a ed.), 1. Reimpressa. Brasília: Ministério da Saúde, 2014. 156.

Vigitel Brasil. Ministério da Saúde. Secretaria de Vigilância em Saúde. Departamento de Vigilância de Doenças e Agravos não Transmissíveis e Promoção da Saúde. Vigitel Brasil 2018: vigilância de fatores de risco e proteção para doenças crônicas por inquérito telefônico: estimativas sobre frequência e distribuição sociodemográfica de fatores de risco e proteção para doenças crônicas nas capitais dos 26 estados brasileiros e no Distrito Federal em 2018. Brasília: Ministério da Saúde, 2019. 132 . 
Freitas-Silva, O., Souza, A. M., \& Oliveira, E. M. M. Potencial da ozonização no controle de fitopatógenos em pós-colheita. In: Luz, W. C. da. (org.). Revisão anual de patologia de plantas. 1.ed. Passo Fundo: Gráfica e Editora Padre Berthier dos Missionários da Sagrada Família, 21, 96-130, 2013.

Guerra, A. M. M., Santos, D. S., Silva, P. S., \& Santos, L. B. Perfil dos consumidores e comerciantes de hortaliças em feira livre na cidade de Barra, BA. Tecnologia \& Ciência Agropecuária, João Pessoa, 12(4), 39-45, 2018.

Instituto Brasileiro de Geografia e Estatística - IBGE. Barra - IBGE Cidades. Recuperado de: <https://cidades.ibge.gov.br/brasil/ba/barra/panorama>.

Kist, B. B., Beling, R. R., Carvalho, C., \& Santos, C. E. Anuário Brasileiro de Horti\&fruti 2019. Santa Cruz do Sul: Editora Gazeta Santa Cruz, 2018. 96.

Marques, R. W. C., \& Caixeta Filho, J. V. Análise das operações de transporte de frutas e hortaliças no Estado de São Paulo: um estudo comparativo. In: 46 Congresso Brasileiro De Economia E Sociologia Rural, Rio de Janeiro, 38. 2000. Anais... Rio de Janeiro, 2000.

Rosa Neto, C., Almeida, C. O., Collares, D. G., \& Santos, C. A. Comportamento do consumidor de frutas em Rondônia: Um estudo de caso. XLIV Congresso Da Sober "Questões Agrárias, Educação No Campo E Desenvolvimento". Fortaleza, 17. 2006.

Perosa, J. M. Y., Tarsitano, M. A. A., Martins, M. I. E. G., Pigatto, G., \& Antonangelo, A. Perfil do consumidor de frutas em cidades do interior do Estado de São Paulo - SP. Revista Brasileira de Fruticultura, Jaboticabal - SP, 34(4), 1084-1090

Silva, D. S. O., \& Costa, C. C. Identificação dos consumidores de hortaliças da feira livre de Pombal-PB: aspectos socioeconômicos e culturais. Revista Verde 6, 56-60. 2011.

Souza, C. A. S., \& Pinto, F. R. L. Extensão rural na cidade de Barra-Ba - Uma análise da produção da agricultura familiar. 2014. Recuperado de <https://www.webartigos.com/artigos/ extensao-rural-na-cidade-de-barra-ba-uma-analise-da-producao-da-agricultura-familiar/ 127723>. 
Teixeira, B. A. Caracterização dos fatores de escolha e compra de frutas e hortaliças pela população adulta do Distrito Federal. Universidade de Brasília. Brasília-DF, 128. 2013.

World Health Organization; Food and Agriculture Organization of the United Nations. Diet, nutrition and the prevention of chronic diseases. Report of a Joint WHO/FAO Expert Consultation. Geneva: World Health Organization; 2003. 916.

Zaro, M. Desperdício de alimentos: velhos hábitos, novos desafios. Caxias do Sul, RS: Educs, 2018. 417.

\section{Porcentagem de contribuição de cada autor no manuscrito}

$$
\text { Iurimon Oliveira }-15 \%
$$

César Fernandes Aquino - 15\%

Antônia Mirian Nogueira de Moura Guerra - 15\%

Francisco das Chagas Bezerra Neto - $14 \%$

Clarice Ribeiro Alves Caiana - 13\%

Aline Carla de Medeiros - 14\%

Patrício Borges Maracajá - 14\% 